Gingivitis ve

periodontitis

hastalarında cerrahi

olmayan periodontal

tedavinin algılanan

ağrı düzeyleri üzerine

etkilerinin cinsiyetlere

göre karşılaştırılması

\section{Comparison of the effects of non-surgical periodontal treatment on perceived pain levels in gingivitis and periodontitis patients by gender}

\author{
Dr. Öğretim Üyesi Fatma Uçan Yarkaç \\ Necmettin Erbakan Üniversitesi \\ Diş Hekimliği Fakültesi, Periodontoloji A.D., Konya \\ Orcid ID: 0000-0001-8126-585X
}

\section{Arş. Gör. Dilek Özkan Şen}

Necmettin Erbakan Üniversitesi

Diş Hekimliği Fakültesi, Periodontoloji A.D., Konya

Orcid ID: 0000-0002-0531-1217

Doç. Dr. Elif Öncü

Necmettin Erbakan Üniversitesi

Diş Hekimliği Fakültesi, Periodontoloji A.D., Konya

Orcid ID: 0000-0002-5774-4604

Geliş tarihi: 6 Mayıs 2020

Kabul tarihi: 1 Aralık 2020

doi: 10.5505/yeditepe.2021.31932

\section{Yazışma adresi:}

Necmettin Erbakan Üniversitesi Diş Hekimliği

Fakültesi Periodontoloji A.D 42050, Konya

Tel: (0332) 2200045-1247

E-posta: dilekozkan19@hotmail.com
ÖZET

Amaç: Cerrahi olmayan periodontal tedavi hastalarda ağrıyla birlikte anksiyete ve strese neden olabilir. Hastaların ağrıyı ifade ediş şekilleri ve bireylerin ağrı algıları cinsiyetler arasında farklılık gösterir. Bu çalışmanın amacı, cerrahi olmayan periodontal tedavinin kadın ve erkek bireylerdeki ağrı algısı düzeyleri üzerine etkilerini değerlendirmektir.

Gereç ve Yöntem: Çalışmaya 45'i kadın, 34'ü erkek toplam 79 birey dahil edildi. Bireylerin periodontal durumları plak indeks (Pi), gingival indeks (Gi), sondalamada kanama (SK) ve sondalanabilir cep derinliği (SCD) ölçümleriyle belirlendi. Hastaların anksiyete ve korku düzeyleri Modifiye Dental Anksiyete SkalasI (MDAS) ve Dental Anksiyete ve Korku indeksi (IDAF-4C) ile ölçüldü. Cerrahi olmayan periodontal tedavi öncesi ve sonrası 1, 3 ve 7. günlerde hastaların ağıı algıları görsel analog skala ile belirlendi.

Bulgular: Kadın ve erkek bireylerdeki periodontal teşhiş, Gi, $\mathrm{PI}$, SKi ve SCD ölçümleri kıyaslandığında gruplar arasında istatistiksel olarak anlamlı farklılık gözlenmedi $(p>0,05)$. MDAS ve IDAF-4C değerlendirildiğinde, gruplar arasında istatistiksel olarak anlamlı farklılık görüldü $(p<0,05)$. Kadın bireyler erkek bireylere kıyasla daha yüksek anksiyete skorlarına sahipti $(p<0,05)$. Cerrahi olmayan periodontal tedavi sonrası ağrı algısı skorları her iki grupta benzer şekilde 1. gün artış gösterirken, 3 ve 7. günlerde ağrı algısında anlamlı bir azalma olduğu gözlendi $(p<0,05)$.

Sonuç: Bu çalışmanın sonuçları doğrultusunda kadınların anksiyete seviyelerinin daha yüksek olduğu ve cerrahi olmayan periodontal tedavinin kadın ve erkek bireylerde benzer bir ağrıya neden olduğu söylenebilir. Cinsiyet dental anksiyete üzerine önemli bir faktörken, ağrı algısını üzerine etkili bir faktör değildir. Cerrahi olmayan periodontal tedavilerde kadın bireylerin daha yüksek anksiyeteye sahip olduğu göz önünde bulundurulmalıdır.

Anahtar kelimeler: Periodontal tedavi, ağrı, anksiyete, cinsiyet.

\section{SUMMARY}

Objective: Non-surgical periodontal therapy (NPT) can cause anxiety and stress as well as pain in patients. The patients' perception and definition of pain differ between genders. The aim of this study was to evaluate the effects of NPT on pain perception levels in male and female patients.

Material and Method: A total of 79 patients, 45 female and 34 male were included in the study. The periodontal status was determined by plaque index (PI), gingival index (GI), bleeding on probing (BoP), and probing pocket depth (PPD) measurements. Anxiety and fear levels of patients were measured with the Modified Dental Anxiety Scale (MDAS) and Dental Anxiety and Fear index (IDAF-4C). Patients' pain perceptions were determined with visual analog scale on pre- and post-treatment 1, 3 and 7. days

Results: No significant differences in the periodontal diagnosis, Pl, Gl, BoP and PPD measurements between the groups 
( $p>0.05)$. There were significant differences in MDAS and IDAF-4C scores between the groups $(p<0.05)$. Female had higher dental anxiety scores compared to male $(p<0.05)$. After NPT, pain scores increased on 1. day, while there was a significant reduction in pain scores on 3 and 7 days in all groups $(p<0.05)$.

Conclusion: According to the results of this study, it can be said that women have higher anxiety levels and non-surgical periodontal therapy causes similar pain in men and women. While gender is an important factor on dental anxiety, it is not an effective factor on pain perception. In NPTs, it should be taken into consideration that female patients have higher anxiety.

Key words: Periodontal therapy, pain, anxiety, gender. Giriş

Periodontal hastalıklar dental plak biyofilmdeki patojenik mikroorganizmalar tarafından başlatılan, mikrobiyal dental plak ile konak immün yanıtı arasındaki etkileşim sonucu ortaya çıkan kronik inflamatuar hastalıklardır. Periodontal dokularda inflamasyon gingival inflamasyon olarak başlar ve tedavi edilmediği takdirde periodontal ligament ve alveoler kemik kaybına neden olabilir.' Periodontal hastalıkların tedavisinde öncelikle inflamasyonun azaltılması veya ortadan kaldırılması için etiyolojik faktörlerin eliminasyonu amaçlanır. Kişisel ve profesyonel bakımı içeren uygun destekleyici periodontal bakım da inflamasyonun yeniden başlamasının önlenmesinde oldukça önemlidir. Bu amaçla en yaygın kullanılan tedavi cerrahi olmayan periodontal tedavidir. Cerrahi olmayan periodontal tedaviyle ilgili güncel araştırmalar, bakterileri kök yüzeyinden uzaklaştırmak için yeni yaklaşımlara, ${ }^{2-7}$ subgingival enstrümantasyonun klinik sonuçlarının, prognostik faktörlerinin tanımlanmasına ve tedavi stratejisinin optimizasyonuna odaklanmaktadır. ${ }^{8-18}$ Hastaların algılarını ve yaşam kalitesi sonuçları gibi hasta merkezli sonuçları araştıran araştırmalar, özellikle tedavi stratejisinin optimize edilmesinde oldukça önemlidir. ${ }^{19-21}$

Cerrahi olmayan periodontal tedavinin hasta algısı ve yaşam kalitesi üzerindeki etkisi hakkında nispeten az şey bilinmektedir. Mekanik enstrümantasyon sonrası dişeti çekilmesi, yumuşak doku travması, kök hasarı, hassasiyet ve ağrı duyulabilir ve bireylerin yaşam kalitesini etkilenebilir. ${ }^{22}$ Cerrahi olmayan periodontal tedaviler hastalarda ağrıyla birlikte anksiyete ve strese de neden olabilmektedir. Diş tedavisi hakkındaki korku ve endişe birçok hasta için önemli bir sorundur ve tedaviye engel olabilir. Bazı hastalar aşırı korkuları nedeniyle diş hekimlerinden tamamen kaçınırlar. ${ }^{23,24}$ Bir diş hekimine yapılan ziyaret sırasında daha önce acı veren veya olumsuz deneyim, diş kaygısının en yaygın sebebidir. Dental anksiyete ve kaygı yaş, ruhsal durum, cinsiyet gibi faktörlerle ilişkili olabilir. ${ }^{25}$ Son yıllarda dental uygulamaların ağrı ve anksiyete ile olan ilişkisini inceleyen birçok çalışmada, cinsiyetin dental anksi- yete ile ilişkili olduğu bildirilmiştir. ${ }^{15,26,27}$

Ağrı, yoğun veya zararlı uyaranlara karşı gelişen bir duygudur. Karmaşık ve öznel bir fenomen olduğu için ağrıyı tanımlamak zordur. ${ }^{28}$ Uluslararası Ağrı Teşkilatı́na göre ağrı, vücudun herhangi bir yerinden kaynaklanan gerçek veya olası bir doku hasarı ilişkili, hoş olmayan duyusal ve duygusal deneyimlerdir ve daima subjektiftir. ${ }^{29}$ Hastaların ağrıyı ifade ediş şekilleri ve bireylerin ağrı algıları cinsiyetler arasında farklılık gösterir. Kadınlarda hormonal değişiklikler ve emosyonel duygu durum değişiklerinin fazla olması sebebiyle kadınlar ağrı ve strese karşı erkeklere göre daha duyarlıdır. ${ }^{30}$ Bazı araştırmalar kadınların ağrıya daha duyarlı olduğunu belirtirken, ${ }^{31}$ cinsiyetler arasında farklılık olmadığını ileri süren çalışmalar da mevcuttur. ${ }^{26,32,33} \mathrm{Bu}$ nunla birlikte cerrahi olmayan periodontal tedavinin kadın ve erkek bireylerdeki ağrı algısı üzerine etkisini değerlendiren çok az çalışma vardır. ${ }^{22,34-36}$

Bu çalışmada, cerrahi olmayan periodontal tedavinin kadın ve erkek bireylerdeki ağrı algısı düzeyleri üzerine etkilerinin incelenmesi amaçlanmaktadır.

\section{GEREÇ VE YÖNTEM}

Çalışmaya Necmettin Erbakan Üniversitesi Diş Hekimliği Fakültesi Periodontoloji Anabilim Dalına başvuran yaşları 18-65 arasında değişen 45'i kadın, 34'ü erkek toplam 79 birey dahil edildi. Çalışmaya katılmayı kabul eden tüm bireylerin yazıı ve sözlü onamları alındı. Çalışma protokolü Helsinki Bildirgesi yönergelerine uyularak gerçekleştirildi ve Necmettin Erbakan Üniversitesi Diş Hekimliği Fakültesi İlaç ve Tıbbi Cihaz Dışı Klinik Araştırmalar Etik Kurulu tarafından onaylandı (Karar no:2020.03).

Çalışmaya dahil edilme kriterleri: ağzında en az 20 dişi bulunması, herhangi bir sistemik hastalığı bulunmaması, psikolojik herhangi bir hastalığı olmaması, son 6 ayda analjezik ve/veya antibiyotik ilaç kullanmaması, hamilelik, laktasyon veya menstruel siklus döneminde olmaması, son 6 ayda herhangi bir periodontal tedavi almaması ve periodontal muayene sonucu gingivitis ve/veya periodontitis tanısı konulmasıdır. Klinik ve radyografik muayene sonucunda, \% 10'dan az sondalamada kanama, $\leq 3 \mathrm{~mm}$ periodontal cep derinliği olan ve ataşman kaybı olmayan bireyler gingivitis tanısı; komşu olmayan en az 2 dişte interdental klinik ataşman kaybı ya da bukkal veya oral yüzeyde $\geq 3 \mathrm{~mm}$ cep derinliği ile birlikte $\geq 3 \mathrm{~mm}$ klinik ataşman kaybı bulunan bireyler periodontitis tanısı konuldu. ${ }^{37}$ Diş çürüğü, dişeti çekilmesi, hassasiyet gibi ağrı durumunu etkileyebilecek herhangi bir dental şikayeti bulunan bireyler de çalışma dışı bırakıldı.

Çalışmaya dahil edilen tüm bireylerin demografik verileri kaydedildikten sonra tüm ağız klinik ve radyografik periodontal değerlendirmeler uzman bir klinisyen tarafından gerçekleştirildi (EÖ). Plak indeksi, ${ }^{38}$ gingival indeksi, ${ }^{39}$ sondalamada kanama ve sondalanabilir cep derinliği ölçümleri kaydedildi. 
Bireylerin dental anksiyete ve korku seviyeleri tedavi öncesi Modifiye Dental Anksiyete Skalasını (MDAS) ve Dental Anksiyete ve Korku İndeksi (IDAF-4C+) ${ }^{40}$ kullanılarak değerlendirildi. Humphris ve ark. ${ }^{41}$ tarafından geliştirilen MDAS, 5 sorudan oluşan likert tip bir ölçek olup, bireylerin dental anksiyete düzeylerini ölçmektedir. MDAS skor değeri $\geq 19$ olan katılımcılar yüksek dental kaygı düzeyine sahip bireyler olarak değerlendirilmektedir. ${ }^{42}$ Dental Anksiyete ve Korku indeksi Armfield tarafından geliştirildi. ${ }^{43}$ Ölçek diş hekimi ve dental tedavilerden korku hissi ve korkunun bileşenlerine ilişkin davranışsal, duygusal bilişsel ve fizyolojik olmak üzere 4 boyuttan oluşmaktadır. Türkiye'de yapılan çalışmalarda skalaların geçerli ve güvenilir olduğu bildirildi. ${ }^{40}$ Katılımcılardan kendilerine verilen ölçekleri periodontal tedavi öncesi klinikteki sessiz ve sakin bir odada doldurmaları istendi.

Cerrahi olmayan periodontal tedavi kapsamında yapılan diş taşı temizliği ve kök yüzey düzleştirilmesi işlemleri, lokal anestezi altında periodontal el aletleri ve ultrasonik cihazlar kullanılarak uzman bir klinisyen tarafından gerçekleştirildi (DÖ). Tedavi süresi ve/veya operatörün bireylerin ağrı algısı üzerindeki etkisini minimalize etmek için tedavi süreleri 2 saat ile sınırlandırıldı. Tedavi sonrası bireylere uygun şekilde diş fırçalama ve diş ara yüzey temizliğini içeren standart ağız hijyeni talimatları verildi.

Cerrahi olmayan periodontal tedaviye başlanmadan önce ve periodontal tedaviler tamamlandıktan sonra hastalardan duydukları ağrıyı Görsel Analog Skalasını (Visual Analogue Scale "VAS") 35 kullanarak belirtmeleri ve bireylerin ağrı seviyesi ile orantılı olacak şekilde ağrı şikayetlerini 0 (hiç) ile 100 (çok şiddetli) arasında değişen bir ölçekte tedavi öncesi ve tedavi sonrası 1, 3 ve 7. günlerde, sakin bir ortamda işaretleme yapmaları istendi.

Katılımcılardan elde edilen veriler SPSS 21.0 (Statistical Package for Social Sciences) paket programı kullanılarak analiz edildi. Demografik veriler tanımlayıcı olarak Ki-kare testi ile değerlendirildi. Gruplar arası ağrı ve anksiyete Mann- Whitney U testi ile, zamana bağlı grup içi ağrı durumundaki değişimler ise Friedman testi ile belirlendi. $\mathrm{p}<0,05$ istatistiksel olarak anlamlı kabul edildi.

\section{BULGULAR}

Çalışmaya 45 kadın ve 34 erkek olmak üzere toplam 79 kişi dahil edildi. Çalışmaya dahil edilen hastaların demografik ve klinik özellikleri Tablo 1'de verildi.
Tablo 1. Kadın ve erkek bireylerin demografik ve klinik verileri.

\begin{tabular}{|c|c|c|c|}
\hline & Kaden $(n=45)$ & Erkek $(n=34)$ & $p$ \\
\hline Yas (Ort $\pm \mathrm{SD})$ & $40,64 \pm 9,83$ & $42,14 \pm 12,09$ & 0,494 \\
\hline \multicolumn{4}{|l|}{ Periodontal Klinik Parametreler (Ort \pm SD) } \\
\hline Plak indeksi & $1,88 \pm 0,43$ & $1,76 \pm 0,43$ & 0,571 \\
\hline Gingival indeks & $1,80 \pm 0,72$ & $1,67 \pm 0,80$ & 0,353 \\
\hline Sondalanabilir cep derinliği (mm) & $4,17 \pm 1,64$ & $3,85 \pm 1,57$ & 0,347 \\
\hline \multicolumn{4}{|l|}{ Sondalamada kanama n (\%) } \\
\hline \%10'dan az & $4(8,9)$ & $6(17,6)$ & 0,246 \\
\hline$\% 10$ 'dan fazla & $41(91,1$ & $28(82,4)$ & \\
\hline \multicolumn{4}{|l|}{ Periodontal teşhis $n(\%)$} \\
\hline Gingivitis & $14(31,1)$ & $14(41,2)$ & 0,354 \\
\hline Periodontitis & $31(68,9)$ & $20(58,8)$ & \\
\hline \multicolumn{4}{|l|}{ Ĕgitim durumu n(\%) } \\
\hline Ilköğretim & $29(64,4)$ & $19(55,9)$ & \\
\hline Lise & $10(22,2)$ & $5(14,7)$ & 0,194 \\
\hline Üniversite & $6(13,3)$ & $10(29,4)$ & \\
\hline Total-MDAS (Ort $\pm \mathrm{SD})$ & $10,77 \pm 4,00$ & $7,82 \pm 2,97$ & $0,000^{\circ}$ \\
\hline Total-IDAF-4C+(Ort $\pm \mathrm{SD})$ & $7,28 \pm 6,72$ & $4,41 \pm 6,06$ & $0,026^{\circ}$ \\
\hline
\end{tabular}

Ort; Ortalama, SD; standart deviasyon, MDAS; Modifiye Dental Anksiyete Skalası, IDAF-4C+; Dental Anksiyete ve Korku Indeksi

* Mann-Whitney U testi; $p<0,05 * *$ Ki kare testi; $p<0,05$

Çalışmaya dahil bireylerin yaş ortalaması kadınlarda

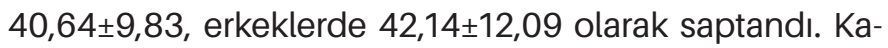
dınların \%64,4'ü, erkeklerin \%55,9'u düşük eğitim seviyesine sahipti.

Periodontal klinik değerlendirmede kadın bireylerin \%31,1'i, erkeklerin \%41,2'si gingivitis tanısı; kadın bireylerin $\% 68,9^{\prime} u$, erkek bireylerin $\% 58,8^{\prime} i$ periodontitis tanısı aldı. Kadın ve erkek bireylerdeki periodontal teşhiş, plak indeksi, gingival indeksi, sondalamada kanama değerleri ve sondalanabilir cep derinliği ölçümleri kıyaslandığında gruplar arası istatistiksel olarak anlamlı farklıık gözlenmedi $(p>0,05)$.

Cerrahi olmayan periodontal tedavi sonrası bireylerde herhangi bir komplikasyon gözlenmemiştir. Tedavi sonrası erkek bireylerin ağrı algısı skorları 1. günde anlamlı bir artış gösterirken $(p<0,05)$, kadın bireylerin ağrı skorlarında istatistiksel olarak anlamlı bir farklılık olmadığı görüldü ( $p>0,05)$. 3. ve 7. günlerde ise hem erkek hem de kadın bireylerin ağıı algısında anlamlı bir azalma olduğunu belirlendi $(p<0,05)$. Gruplar cerrahi olmayan periodontal tedavi öncesi ve tedavi sonrası 1., 3. ve 7. ağrı algısı skorları açısından karşılaştırıldığında aralarında anlamlı bir fark saptanmadı ( $p=0,783, p=0,932, p=0,221, p=0,193$ ) (Grafik 1). 


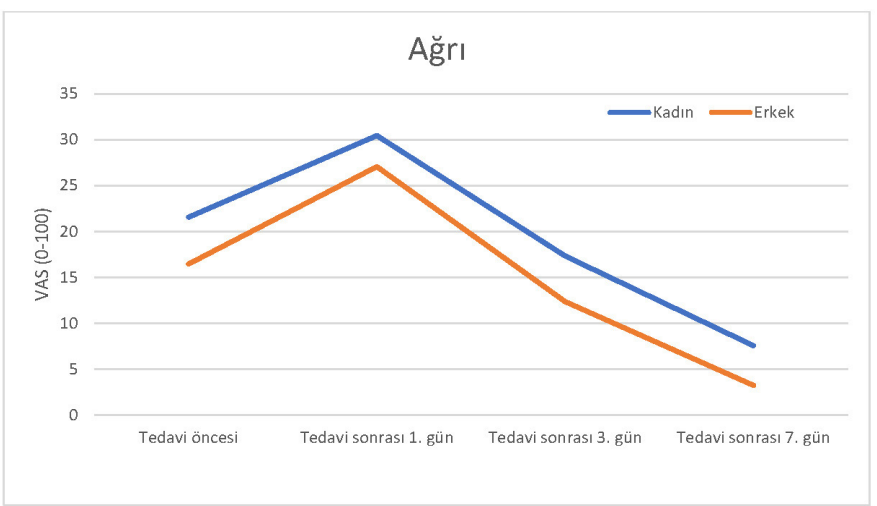

Grafik 1. Kadın ve erkek bireylerin tedavi öncesi tedavi sonrası ağrı algısı değerleri.

Erkek bireylerdeki periodontal hastalık ile ağrı skorları arasındaki ilişki değerlendirildiğinde, gingivitisli ve periodontitisli bireylerin ağıı algısı skorları benzerdi $(p>0,05)$. Ilaveten, periodontitis ve gingivitis teşhisi konulan kadın bireyler arasındaki ağrı algısı skorları tedavi öncesi ve sonrası anlamlı farklılık göstermedi $(p>0,05)$ (Tablo 2).

Tablo 2. Gingivitisli ve periodontitisli kadın ve erkek bireylerdeki dental anksiyete, dental anksiyete ve ağrı algısı skorları.

\section{Kadm Bireyler Erkek bireyler}

$\begin{array}{lllllll} & \text { Gingivitis } & \text { Periodontitis } & \mathrm{p} & \text { Gingivitis } & \text { Periodontitis } & \mathrm{p} \\ \text { Total-MDAS } & 11,85 \pm 3,37 & 10,29 \pm 4,22 & 0,115 & 7,78 \pm 3,06 & 7,85 \pm 2,99 & 0,823 \\ \text { (Ort } \pm \text { SD) } & & & & & & \\ \text { Total-IDAF- } & 6,78 \pm 5,60 & 7,51 \pm 7,24 & 0,961 & 2,71 \pm 3,56 & 5,60 \pm 7,18 & 0,377 \\ \text { 4C+(Ort } \pm \text { SD) } & & & & & & \\ \text { VAS-Tedavi } & 27,14 \pm 24,62 & 19,03 \pm 25,08 & 0,324 & 10,00 \pm 16,17 & 21,00 \pm 21,74 & 0,148 \\ \text { öncesi } & & & & & & \\ \text { VAS-Tedavi } & 31,42 \pm 25,97 & 30,00 \pm 29,43 & 0,701 & 23,57 \pm 19,45 & 29,50 \pm 17,31 & 0,323 \\ \text { sonrası 1. gün } & & & & & & \\ \text { VAS- Tedavi } & 15,71 \pm 16,96 & 18,06 \pm 24,41 & 0,809 & 11,42 \pm 17,47 & 13,00 \pm 19,22 & 0,931 \\ \text { sonrası 3. gün } & & & & & & \\ \text { VAS- Tedavi } & 5,71 \pm 10,89 & 8,38 \pm 19,84 & 0,925 & 2,17 \pm 5,78 & 4,00 \pm 11,87 & 0,959 \\ \text { sonrası 7. gün } & & & & & & \end{array}$

Dental Anksiyete ve Korku Indeksi "Mann-Whitney U testi; $p<0,05$

Ort; Ortalama, SD; standart deviasyon, MDAS; Modifiye Dental Anksiyete Skalası, IDAF4C+; Dental Anksiyete ve Korku Indeksi * Mann-Whitney U testi; $p<0,05$

MDAS ve IDAF-4C+ cinsiyetlere göre değerlendirildiğinde kadın ve erkek bireyler arasında istatistiksel olarak anlamlı farklılık görüldü $(p<0,05)$. Kadın hastalar erkek hastalara kıyasla daha yüksek anksiyete skorlarına sahipti $(p<0,05)$ (Tablo 3 ve 4).
Tablo 3. Kadın ve erkek bireylerdeki MDAS maddelerine göre genel cevap dağılımı.

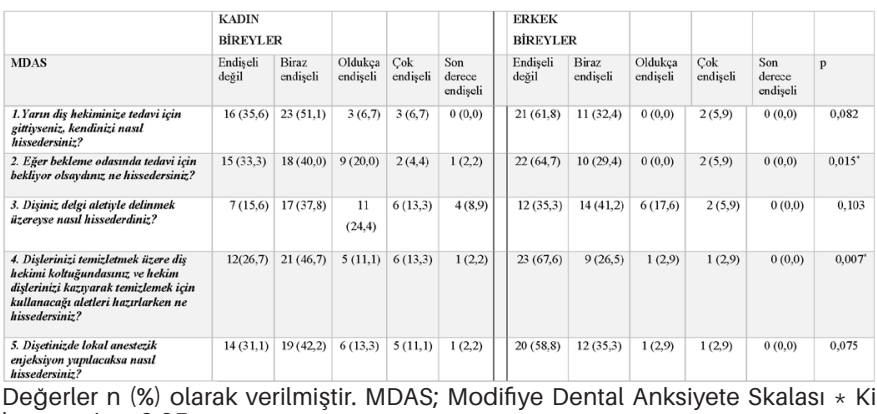
kare testi; $p<0,05$

Tablo 4. Kadın ve erkek bireylerdeki IDAF-4C+ maddelerine göre genel cevap dağılımı.

\begin{tabular}{|c|c|c|c|c|c|c|c|c|c|c|c|}
\hline \multirow[b]{2}{*}{$\mathrm{DDAF}-4 \mathrm{C}+$} & \multicolumn{3}{|c|}{ KADIN BiREYLER } & \multirow[b]{2}{*}{$\begin{array}{l}\substack{\text { Olctulkan } \\
\text { katllyoru }} \\
\text { and }\end{array}$} & \multirow[b]{2}{*}{$\begin{array}{l}\text { Tamamen } \\
\text { katlyyoum }\end{array}$} & \multicolumn{3}{|c|}{ ERKEK BIREYLER } & \multirow[b]{2}{*}{\begin{tabular}{|l}
$\begin{array}{l}\text { Olduksa } \\
\text { kathlyoru }\end{array}$ \\
\end{tabular}} & \multirow[b]{2}{*}{\begin{tabular}{|l} 
Tamannen \\
kathlyonu
\end{tabular}} & \\
\hline & Katlinyychum & 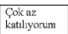 & \begin{tabular}{|l}
$\begin{array}{l}\text { Birna2 } \\
\text { kathyoru }\end{array}$ \\
\end{tabular} & & & $\begin{array}{l}\text { Kathrnyo } \\
\text { fun }\end{array}$ & \begin{tabular}{|l|}
$\begin{array}{l}\text { Colk az } \\
\text { kathyoru }\end{array}$ \\
\end{tabular} & \begin{tabular}{|l}
$\begin{array}{l}\text { Biraz } \\
\text { katlyor }\end{array}$ \\
\end{tabular} & & & \\
\hline 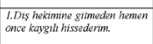 & $12(26,7)$ & $10(22,2)$ & $\frac{m}{10(22,2)}$ & $\frac{m}{11(24,4)}$ & $2(4,4)$ & $17(50,0)$ & $\frac{m}{3(8,8)}$ & \begin{tabular}{|l|l}
$\min$ \\
$129,4)$ \\
$(22,4)$
\end{tabular} & $\frac{m}{3(8,8)}$ & $\frac{m}{1(2,9)}$ & 0,086 \\
\hline 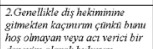 & $22(48,9)$ & $2(4,4)$ & $12(26,7)$ & $7(15,6)$ & $2(4,4)$ & $26(76,5)$ & $3(8,8)$ & $2(5,9)$ & $1(2,9)$ & $2(5,9)$ & $0,028^{\prime}$ \\
\hline 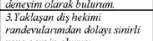 & $28(62,2)$ & $7(15,6)$ & $4(8,9)$ & $5(11,1)$ & $1(22)$ & $28(82,4)$ & $2(5,9)$ & $2(5,9)$ & $2(5,9)$ & $2(5,9)$ & 0,095 \\
\hline 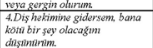 & $3+(75,6)$ & $4(8,9)$ & $+(8,9)$ & $2(4+4)$ & $1(2,2)$ & $30(88,2)$ & $0(0,0)$ & $3(8.8)$ & $0(0,0)$ & $1(2,9)$ & 0.292 \\
\hline 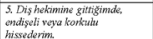 & $18(4,0)$ & $8(17,8)$ & $12(26,7)$ & $5(11,1)$ & $2(4,4)$ & $24(70,9)$ & $4(11,8)$ & $3(8,8)$ & $0(0,0)$ & $3(8,8)$ & $0,022^{\prime}$ \\
\hline 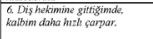 & $24(53,3)$ & $3(6,7)$ & $11(24,4)$ & $7(15,6)$ & $0(0,0)$ & $22(64,7)$ & $6(17,5)$ & $4(11,8)$ & $0(0,0)$ & $2(5,9)$ & 0,017 \\
\hline 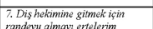 & $35(77,8)$ & $1(2,2)$ & $5(11,1)$ & $3(6,7)$ & $1(2,2)$ & $30(88,2)$ & $1(2,9)$ & $2(5,9)$ & $1(2,9)$ & $0(0,0)$ & 0,703 \\
\hline 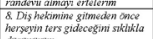 & $37(82,2)$ & $2(4,4)$ & $2(4,4)$ & $1(2,2)$ & $3(6,7)$ & 27 & $0(0,0)$ & $5(17,6)$ & $0(0,0)$ & $1(2,9)$ & 0,188 \\
\hline
\end{tabular}

Degerter n (\%) olarak veritmiştir. IDAF-4C+; Dehtal Anksiyete ve Korku índeksi * Ki kare testi; $p<0,05$

Periodontal durum ile kadın ve erkek bireylerin dental anksiyete ve korku seviyeleri değerlendirildiğinde, gingivitisli ve periodontitisli bireylerin dental anksiyete ve korku seviyeleri arasında istatistiksel olarak anlamlı farklılık gözlendi ( $p>0,05)$ (Tablo 2).

\section{TARTIŞMA}

Periodontal tedavi sonrası oluşan ağrı, tedavi öncesinde hissedilen anksiyete ve korku seviyeleri sebebiyle farklılıklar oluşturabileceği için bu çalışmada tüm periodontal hastalıkların tedavisinde başlangıç tedavisi olarak uygulanan cerrahi olmayan periodontal tedavinin kadın ve erkek hastalardaki ağrı algısı üzerine etkisi incelendi. Tedavi sonrası gruplardaki bireylerin ağrı algısı ilk gün artarken, ilerleyen günlerde ağrı algısının azaldığı görüldü. İlaveten kadın bireyler erkek bireylere kıyasla daha yüksek anksiyeteye sahipti. Tedavi sonrası gruplar arasındaki ağrı algısı kadınlarda nispeten daha yüksek olsa da gruplar arasında ağrı algısı açısından istatistiksel olarak anlamlı farklılık bulunamamıştır.

Dental anksiyete dental tedavi gören hastalarda çok sık karşılaşılan, hekim ve hasta yönünden tedaviye olan motivasyonu bozabilen önemli bir problemdir. ${ }^{44}$ Dental anksiyeteyi etkileyen en önemli faktörler cinsiyet, yaş, eğitim durumu, bireylerin diş hekimine gitme sıklığı ve önceki dental ziyaret deneyimleridir. Marakoğlu ve ark. ${ }^{45}$ yaptıkları çalışmalarında, dental anksiyete sendromunun sıklıkla 20 yaş altı çocuk ve gençlerde, kadınlarda, kırsalda yaşayan ve daha önce herhangi bir diş tedavisi yaptırmamış, eğitim seviyesi düşük hastalarda daha sık olduğunu belirtmişlerdir. Literatürde kadın hastaların erkeklere göre fazla dental anksiyeteye sahip olduğu görüşü hakimdir.46-48 Danimarkalı yetişkinler arasındaki anksiyete seviyelerini 
Dental Anksiyete Ölçeği (DAS) ve Diş Korku Anketi ile değerlendiren bir çalışmada anksiyete ile cinsiyet, eğitim ve gelir düzeyi arasında anlamlı bir ilişki olduğu belirtilmiştir. ${ }^{49}$ Ay ve ark. ${ }^{50}$ ile Muğlalı ve Kömerik ${ }^{51}$ çalışmalarında kadınların kaygı ve anksiyetenin seviyesinin erkeklerden fazla olduğunu görmüşlerdir. Berggren ve Meynert ${ }^{52}$ diş hekimi korkusuyla cinsiyet arasındaki ilişkiyi araştırmış ve kadınlardaki diş hekimi korkusunun daha fazla olduğunu gözlemlemişlerdir. Ancak aksi görüşü savunan çalışmalar da mevcuttur. Özdemir ve ark. ${ }^{53}$ erkeklerde anksiyete skorlarının yüksek olduğunu bildirmiştir. Çağırankaya ve Kansu ${ }^{54}$ diş hekimliği öğrencilerinde dental anksiyete düzeylerini değerlendirdikleri çalışmalarında cinsiyetler arasında farklılık olmadığını rapor etmişlerdir. Benzer şekilde Kara $^{55}$ peridontal tedavi esnasındaki anksiyete ile yaş, cinsiyet ve diş hekimine gitme durumu arasındaki ilişkiyi değerlendirdikleri çalışmalarında anksiyete ile yaş arasında anlamlı bir ilişki olduğunu bildirirken, cinsiyetle anksiyete arasında anlamlı bir ilişki olmadığını rapor etmişlerdir. Çalışmamızda da kadınların daha çok anksiyeteye sahip olduklarını belirten çalışmalara benzer şekilde kadın hastaların MDAS ve IDAF-4C+ verileri erkek bireylere kıyasla daha yüksek bulundu. Kadınların daha yüksek dental anksiyeteye sahip olmaları, kadınların ağrı uyaranına toleransının erkeklere göre daha düşük olması aynı zamanda erkeklerin kaygılarını açık şekilde dile getirmekten korkmaları nedeniyle olabilir. ${ }^{56}$

Ağrının ölçülmesi için görsel analog skalanın güvenilir ve geçerli bir yöntem olduğu gösterilmiştir. ${ }^{31}$ Aynı zamanda periodontal tedavi ilişkili ağrıyı ve periodontal tedaviyi takiben dentin hassasiyetini değerlendirmede başarıyla kullanılmıştır. 3,4,13,20,27,57,58 Çalışmamızda da cerrahi olmayan periodontal tedavi sonrası ağrı görsel analog skala kullanılarak değerlendirildi. Kadın ve erkek bireyler arasında ağrı düzeylerini görsel analog skala kullanarak değerlendiren çalışmalar cinsiyetler arasında ağrı algısının farklılık gösterdiğini bildirmektedir. ${ }^{34-36}$ Pihlstrom ve ark. ${ }^{59}$ diştaşı temizliği ve kök yüzey düzeltimi işlemi sonrası kadınların ağrı hissetmeleri nedeniyle daha fazla analjezik tükettiklerini görmüşlerdir. Aksine başka bir çalışmada cerrahi olmayan periodontal tedavi sonrası kadın ve erkek hastalarda ağrı düzeylerinde farklılık olmadığını rapor etmişlerdir. ${ }^{60}$ Akçalı ve ark. ${ }^{22}$ çalışmalarında kronik periodontitisli bireylerde cerrahi olmayan periodontal tedavi sonucu ağrı düzeyi ile cinsiyet ilişkisini araştırmış, ağrı algısının cinsiyetler arasında benzerlik gösterdiğini bildirmişlerdir. Ağrı hem psikolojik hem de fiziksel komponentleri içerdiği için değerlendirilmesi zordur ve ağrının değerlendirilmesinde genellikle bireyleri anksiyete seviyeleri kontrol edilmeye çalışılmıştır, çünkü anksiyete seviyeleri yüksek olan bireylerde ağrı algısının da yüksek olduğu gözlenmiştir. Literatüre göre genel bir kanı olarak kadınlar erkeklerden ağrıya daha fazla duyarlıdır. ${ }^{56} \mathrm{Bu}$ durumun östro- jen ve progesteron seviyelerindeki değişimler nedeniyle kaynaklandığı ileri sürülmektedir.15,61,62 Çalışmamızda da kadın hastaların ağrının affektif komponentini etkilediği belirtilen anksiyete verilerinin erkeklerinkinden yüksek bulunması bu sonuçları doğrulamaktadır. Kadın bireylerin erkeklere göre daha yüksek anksiyete sahip olmasına karşın cerrahi olmayan periodontal tedavi sonrası bireylerin ağrı algısı benzerlik göstermiştir. Hem kadın hem de erkek bireyler 1. günde daha fazla ağrı duyduklarını, 3. ve 7. günlerde ise hissedilen ağrı seviyelerinde azalma olduğunu belirtmişlerdir. Bu bulgular bireylerin anksiyete seviyesinin algılanan ağrı seviyesi üzerinde tek başına etkili olmadığını düşündürmektedir. Diğer taraftan farklı periodontal hastalığa sahip bireylerin ağrı algılarının da farklılık göstermesinin beklenmesine karşın ${ }^{60}$ çalışmamızda periodontal durum ile bireylerin ağrı algıları arasında bir ilişki bulunamamıştır. Ağrı seviyeleri tedavi sonrası cinsiyetler arasında sayısal olarak farklılık göstermesine rağmen istatistiksel bir fark saptanmaması psikolojik faktörler, ırk, yaş, önceki dental deneyimler gibi hastalara bağlı değişkenlerin farkılıklarından kaynaklanabilirken, tedavinin zamanı ve süresi ve çalışma dizaynı da bu durumu etkiyebilir.

\section{SONUÇ}

Bu çalışmanın sonuçları doğrultusunda kadınların anksiyete seviyelerinin daha yüksek olduğunu ve cerrahi olmayan periodontal tedavi kadın ve erkek bireylerde benzer bir ağrıya neden olduğunu söylenebilir.

\section{KAYNAKLAR}

1. Burt B. Position paper: epidemiology of periodontal diseases. J Periodontol 2005;76:1406-1419.

2. Ambrosini P, Miller N, Briançon S, Gallina S, Penaud J. Clinical and microbiological evaluation of the effectiveness of the Nd: YAG laser for the initial treatment of adult periodontitis: A randomized controlled study. J Clin Periodontol 2005;32:670-676.

3. Kocher T, Fanghänel J, Schwahn C, Rühling A. A new ultrasonic device in maintenance therapy: perception of pain and clinical efficacy. J Clin Periodontol 2005;32:425429.

4. Hoffman A, Marshall R, Bartold P. Use of the Vector $^{\mathrm{TM}}$ scaling unit in supportive periodontal therapy: a subjective patient evaluation. J Clin Periodontol 2005;32:10891093.

5. Qadri T, Miranda L, Tuner J, Gustafsson A. The shortterm effects of low-level lasers as adjunct therapy in the treatment of periodontal inflammation. J Clin Periodontol 2005;32:714-719.

6. Schwarz F, Bieling K, Venghaus S, Sculean A, Jepsen $S$, et al. Influence of fluorescence-controlled Er: YAG laser radiation, the Vector $^{\mathrm{TM}}$ system and hand instruments on periodontally diseased root surfaces in vivo. J Periodontol 2006;33:200-208.

7. Sculean A, Schwarz F, Berakdar M, Romanos GE, Arwe- 
iler NB, et al. Periodontal treatment with an Er: YAG laser compared to ultrasoniclnstrumentation: a pilot study. J Periodontol 2004;75:966-973.

8. Apatzidou D, Riggio M, Kinane D. Impact of smoking on the clinical, microbiological and immunological parameters of adult patients with periodontitis. J Clin Periodontol 2005;32:973-983.

9. D'Aiuto F, Ready D, Parkar M, Tonetti MS. Relative contribution of patient-, tooth-, and site-associated variability on the clinical outcomes of subgingival debridement. I. Probing depths. J Periodontol 2005;76:398-405.

10. Jervøe-Storm PM, Semaan E, AlAhdab H, Engel $S$, Fimmers R, Jepsen S. Clinical outcomes of quadrant root planing versus full-mouth root planing. J Clin Periodontol 2006;33:209-215.

11. Darby I, Hodge P, Riggio M, Kinane D. Clinical and microbiological effect of scaling and root planing in smoker and non-smoker chronic and aggressive periodontitis patients. J Clin Periodontol 2005;32:200-206.

12. Preshaw $P$, Heasman $L$, Stacey F, Steen $N$, McCracken $G$, et al. The effect of quitting smoking on chronic periodontitis. J Clin Periodontol 2005;32:869-879.

13. Kocher T, Rodemerk B, Fanghänel J, Meissner G. Pain during prophylaxis treatment elicited by two power-driven instruments. J Clin Periodontol 2005;32:535-538.

14. Koshy G, Kawashima Y, Kiji M, et al. Effects of single-visit full-mouth ultrasonic debridement versus quadrant-wise ultrasonic debridement. J Clin Periodontol 2005;32:734-743.

15. Ozcaka O, Bicakci N, Kose T. Effect of the menstrual cycle on pain experience associated with periodontal therapy. J Clin Periodontol 2005;32:1170-1174.

16. Perry DA, Gansky SA, Loomer PM. Effectiveness of a transmucosal lidocaine delivery system for local anaesthesia during scaling and root planing. $\mathrm{J}$ Clin Periodontol 2005;32:590-594.

17. Quirynen M, Teughels W, Van Steenberghe D. Impact of antiseptics on one-stage, full-mouth disinfection. J Clin Periodontol 2006;33:49-52.

18. Wennström JL, Tomasi C, Bertelle A, Dellasega E. Fullmouth ultrasonic debridement versus quadrant scaling and root planing as an initial approach in the treatment of chronic periodontitis. J Clin Periodontol 2005;32:851859.

19. Suvan JE. Effectiveness of mechanical nonsurgical pocket therapy. Periodontol 2000 2005;37:48-71.

20. Fardal $\varnothing$, Johannessen AC, Linden GJ. Patient perceptions of periodontal therapy completed in a periodontal practice. J Periodontol 2002;73:1060-1066.

21. Tammaro S, Wennström JL, Bergenholtz G. Root-dentin sensitivity following non-surgical periodontal treatment. J Clin Periodontol 2000;27:690-697.

22. Akcalı A, Nizam N, Özçaka Ö, Bıçakcı N, Köse T. Pain levels following non-surgical periodontal treatment and the relation with gender in patients with chronic periodontitis Gulhane Med J 2014; 56: 133-137.

23. Chadwick BL. Assessing the anxious patient. Dent Update 2002;29:448-454.

24. Skaret E, Raadal M, Berg E, Kvale G. Dental anxiety among 18-yr-olds in Norway, Prevalence and related factors. Eur J Oral Sci 1998;106:835-843.

25. Karaman D, Türker T, Kara K, Durukan I, Fidancı MK. Depression and anxiety levels of children and adolescents with ADHD. Gulhane Med J 2013;55:36.

26. Oktay EA, Koçak MM, Şahinkesen G, Toksoy Topçu $F$. The role of age, gender, education and experiences on dental anxiety. Gulhane Med J 2009; 51: 145-148.

27. Karadottir $H$, Lenoir $L$, Barbierato $B$, et al. Pain experienced by patients during periodontal maintenance treatment. J Periodontol 2002;73:536-542.

28. Alpan AL. Comparison of Anxiety and Perception Levels of Patients Undergoing Initial Periodontal Treatment Using Different Instruments. Cumhuriyet Dent $\mathrm{J}$ 2018;21:371-378.

29. Morgan GE, Mikhail MG. Pain management. In: Clinical anesthesiology. 2nd ed. New Jersey: Prentice-Hall International, Inc.; 1996. p. 274-316.

30. Anand KJ, Craig KD. New perspectives on the definition of pain. Pain 1996;67:3-6.

31. McGrath PA. The measurement of human pain. Dental Traumatology 1986;2:124-129.

32. Notermans $S$, Tophoff M. Sex difference in pain tolerance and pain apperception. Psychiatr Neurol Neurochir 1967; 70: 23-29.

33. Woodrow KM, Friedman GD, Siegelaub A, Collen MF. Pain tolerance: differences according to age, sex and race. Psychosom Med 1972;34:548-556.

34. Chung DT, Bogle G, Bernardini $M$, Stephens D, Riggs $\mathrm{ML}$, et al. Pain experienced by patients during periodontal maintenance. J Periodontol 2003;74:1293-1301.

35. Chapman CR, Casey K, Dubner R, Foley K, Gracely $R$, Reading A. Pain measurement: an overview. Pain 1985;22:1-31

36. Ay S, Özdemir D, Öztürk M, Polat S. An assessment of dental anxiety in oral surgery patients. Gulhane Med $J$ 2002;44:395-398.

37. Caton JG, Armitage G, Berglundh T, et al. A new classification scheme for periodontal and peri-implant diseases and conditions-Introduction and key changes from the 1999 classification. J Periodontol 2018;89:S1-S8.

38. Quigley GA, Hein JW. Comparative cleansing efficiency of manual and power brushing. J Am Dent Assoc 1962;65:26-29.

39. Löe $\mathrm{H}$, Silness J. Periodontal disease in pregnancy I. Prevalence and severity. Acta Odontol Scand 1963;21:533-551. 
40. Buldur B, Armfield J. Development of the Turkish version of the Index of Dental Anxiety and Fear (IDAF-4C+): Dental anxiety and concomitant factors in pediatric dental patients. J Clin Pediatr Dent 2018;42:279-286.

41. Humphris G, Freeman R, Campbell J, Tuutti H, D'souza V. Further evidence for the reliability and validity of the Modified Dental Anxiety Scale. Int Dent J 2000;50:367370.

42. Ergüven SS, Işık B, Kılınç Y. Comparative evaluation of dental anxiety and fear levels between first and final year dental students Acta Odontol Turc 2013; 30: 70-76.

43. Armfield JM. Development and psychometric evaluation of the Index of Dental Anxiety and Fear (IDAF-4C+). Psychol Assess 2010;22:279.

44. Köroğlu A, Durkan R. An evaluation of the etiology and the treatment procedures of dental anxiety syndrome encountered in dental applicatıons. J Dent Fac Atatürk Uni 2010;2010:205-212.

45. Marakoğlu I, Demirer AGS, Özdemir UPD, Sezer H. Periodontal Tedavi Öncesi Durumluk Ve Süreklik Kaygi Düzeyi. Cumhuriyet Univ Diş Hek Fak Derg 2003;6:74-79. 46. Bayindir F, Akyil Agdmş, Kavrut R. Protetik Diş Tedavisi Anabilim Dalina Başvuran Hastalarda Dental Anksiyete Skalasi (DAS) Ve Visual Analog Skala (VAS)'Larin Değerlendirilmesi J Dent Fac Atatürk Uni;2003.

47. Bergdahl M, Bergdahl J. Temperament and character personality dimensions in patients with dental anxiety. Eur J Oral Sci 2003;111:93-98.

48. Abrahamsson $\mathrm{KH}$, Berggren $\mathrm{U}$, Hakeberg $\mathrm{M}$, Carlsson SG. The importance of dental beliefs for the outcome of dental-fear treatment. Eur J Oral Sci 2003;111:99-105.

49. Moore R, Birn H, Kirkegaard E, Brødsgaard I, Scheutz F. Prevalence and characteristics of dental anxiety in Danish adults. Community Dent Oral Epidemiol 1993;21:292296.

50. Ay ZY, Erdek Y, Öztürk M, Kılınç G, Bozkurt Y, et al. The analysıs of the dental fear levels of the patıents attendıng Suleyman Demırel Unıversıty Faculty of Dentıstry Cumhuriyet Univ Diş Hek Fak Derg 2005; 8: 12-18.

51. Muğlalı M, Kömerik N. Ağız Cerrahisi ve Anksiyete. Cumhuriyet Univ Diş Hek Fak Derg 2005;8:85.

52. Berggren U, Meynert G. Dental fear and avoidance: causes, symptoms, and consequences. J Am Dent Assoc (1939) 1984;109:247-251.

53. Özdemir A, Özdemir $H$, Coşkun A, Taşveren S. Diş Hekimliği Fakültesinde profitez kliniği ile diğer kliniklerde hasta anksiyetesinin araştırılması. CÜ Diş Hek Fak Derg 2001;4:71-74.

54. Çağirankaya LB, Kansu Ö. Causes and Outcomes of Dental Anxiety in Dental Students. Hacettepe Üni Diş Hek Fak Derg 2005; 29:8-11.

55. Kara C. Evaluatıng the relatıons of the anxıety durıng perıodontal treatment applıcatıon with age, sex and den- tal previous hıstory. J Dent Fac Atatürk Uni 2007; 17: 12-17. 56. Doğaner YÇ, Aydoğan Ü, Yeşil HÜ, Sarı O, Koç B. Genç bireylerde dental anksiyete ve ilişkili faktörler. Gulhane Med J 2015;57:160-164.

57. Matthews DC, McCulloch CA. Evaluating patient perceptions as short-term outcomes of periodontal treatment: A comparison of surgical and non-surgical therapy. J Periodontol 1993;64:990-997.

58. Hegarty A, McGrath C, Hodgson T, Porter S. Patient-centred outcome measures in oral medicine: are they valid and reliable? Int J Oral Maxillofac Surg 2002;31:670674.

59. Pihlstrom BL, Hargreaves KM, Bouwsma OJ, Myers WR, Goodale MB, et al. Pain after periodontal scaling and root planing. J Am Dent Assoc 1999;130:801-807.

60. Canakçi CF, Canakçi V. Pain experienced by patients undergoing different periodontal therapies. J Am Dent Assoc 2007;138:1563-1573.

61. Fillingim RB, Edwards RR, Powell $T$. The relationship of sex and clinical pain to experimental pain responses. Pain 1999;83:419-425.

62. Fillingim RB, Ness T. Sex-related hormonal influences on pain and analgesic responses. Neurosci Biobehav Rev 2000;24:485-501. 